\title{
Predictors of stable return-to-work in non-acute, non-specific spinal pain: low total prior sick-listing, high self prediction and young age. A two-year prospective cohort study
}

Odd Lindell, Sven-Erik Johansson, Lars-Erik Strender

\begin{abstract}
Background: Non-specific spinal pain (NSP), comprising back and/or neck pain, is one of the leading disorders in long-term sick-listing. During 2000-2004, 125 Swedish primary-care patients with non-acute NSP, full-time sick-listed 6 weeks-2 years, were included in a randomized controlled trial to compare a cognitive-behavioural programme with traditional primary care. This prospective cohort study is a re-assessment of the data from the randomized trial with the 2 treatment groups considered as a single cohort. The aim was to investigate which baseline variables predict a stable return-to-work during a 2-year period after baseline: objective variables from function tests, socioeconomic, subjective and/or treatment variables. Stable return-to-work was a return-to-work lasting for at least 1 month from the start of follow-up.

Methods: Stable return-to-work was the outcome variable, the above-mentioned factors were the predictive variables in multiple-logistic regression models, one per follow-up at 6, 12, 18 and 24 months after baseline. The factors from univariate analyzes with a $p$-value of at most .10 were included. The non-significant variables were excluded stepwise to yield models comprising only significant factors $(p<.05)$. As the comparatively few cases made it risky to associate certain predictors with certain time-points, we finally considered the predictors which were represented in at least 3 follow-ups. They are presented with odds ratios (OR) and 95\% confidence intervals.

Results: Three variables qualified, all of them represented in 3 follow-ups: Low total prior sick-listing (including all diagnoses) was the strongest predictor in 2 follow-ups, 18 and 24 months, OR 4.8 [1.9-12.3] and 3.8 [1.6-8.7] respectively, High self prediction (the patients' own belief in return-to-work) was the strongest at 12 months, OR 5.2 [1.5-17.5] and Young age (max 44 years) the second strongest at 18 months, OR 3.5 [1.3-9.1].
\end{abstract}

Conclusions: In primary-care patients with non-acute NSP, the strong predictors of stable return-to-work were 2 socioeconomic variables, Low total prior sick-listing and Young age, and 1 subjective variable, High self-prediction. Objective variables from function tests and treatment variables were non-predictors. Except for Young age, the predictors have previously been insufficiently studied, and so our study should widen knowledge within clinical practice.

Trial registration: Trial registration number for the original trial NCT00488735.

\section{Background}

For many years, spinal pain, comprising back and/or neck pain, was the leading disorder in long-term sick-listing, including disability pensions, in Sweden as all over the industrial world. In 2002, Sweden was the leading country

\footnotetext{
* Correspondence: odd.lindell@ki.se

Center for Family and Community Medicine, Karolinska Institutet, Alfred Nobels allé 12, SE-141 83 Huddinge, Sweden
}

within the European Union in sick-listing for spinal pain [1], which in 2007 resulted in $11.9 \%$ of new disability pensions [2]. Following an international trend [3], the leading position of spinal pain in Sweden since 2005 has been overtaken by depression (in $200713.1 \%$ of new disability pensions) [2]. Most cases of spinal pain concern nonspecific spinal pain (NSP) and are a matter for primary care [4]. In the management of disabling spinal pain, stable 
return-to-work is the ultimate objective [4]. As return-towork is often followed by recurrences of work absence, longitudinal data are required to denote a stable return-towork [5].

Cost-effectiveness in allocating treatment resources requires predictors of return-to-work to be collected by means of both questionnaires and function tests, i.e. tests in which the patient performs some kind of physical activity [6]. While the former are cheap, the latter require substantial personnel resources. Despite an immense amount of research, no gold standard for questionnaires and/or tests has been established for this purpose [6,7]. In the treatment of non-acute NSP, i.e. pain leading to full-time sick-listing for more than 3 weeks [8], evidence-based guidelines advocate a cognitive-behavioural therapeutic approach [4].

During 2000-2004, 125 patients with non-acute NSP were included in a randomized, controlled trial to compare a cognitive-behavioural programme with traditional primary care [9]. A package of function tests and a questionnaire were completed at baseline. The aim of this study was to answer the question "which are the predictors at baseline in non-acute NSP for stable return-to-work during a 2-year period after baseline: objective variables from function tests, socio-economic, subjective and/or treatment variables?"

\section{Methods}

On sick-listing and return-to-work in Sweden

As the employer has the financial responsibility for the 2 initial weeks of sick-listing in Sweden, the available data include only the sick-listing periods exceeding 2 weeks. For the unemployed subjects, however, those data include all periods. Sick-listing, as described in detail in a prior study [9], might have the degrees .25, $.50, .75$ or 1.00 (= full-time). The degree of return-towork $=1.00$ minus the degree of sick-listing, as defined by the Social Insurance Agency. For example, sick-listing $=.75$ equals return-to-work $=.25$ and full-time sick-listing equals non-return-to-work. In response to prolonged sick-listing, the Agency might consider a temporary or permanent disability pension (the temporary form being abolished in 2008), which might have the same degrees as the other forms of sick-listing.

\section{Setting and source population}

The setting was a suburban area in the Southern part of Stockholm County, including 9 municipalities with a population of 466,000 , of whom 288,000 of working age (18-64 years) constituted the source population.

\section{Patients}

One hundred and twenty-five primary-care patients with non-acute NSP were recruited to a randomized controlled trial, which in detail was described in a previous study [9], by 41 family doctors at 13 health centres between August 2000 and January 2004. Recruitment was non-systematic, i.e. it was up to the family doctor on the basis of her or his current motivation and available time to invite a potentially eligible patient. In summary:

The patients were allocated either to a cognitive-behavioural programme at a rehabilitation centre or continued traditional primary care. The criteria for inclusion: 1.Vocationally active, up to and including 59 years of age. 2. Sick-listed full-time for spinal pain at least six weeks (42 days) and at most two years (730 days). 3. Able to fill in forms. The criteria for exclusion: 1. Temporary disability pension or disability pension being paid or in preparation. 2. Primary need for action by a hospital specialist (for example, operation for intervertebral herniation (slipped disc)). 3. Pregnancy or diseases (other than spinal pain) that might make the rehabilitation programme impracticable (for example, advanced pulmonary disease). 4. Whiplash-associated disorders as a primary obstacle to working. 5. Previous rehabilitation at the rehabilitation centre. 6. Other multidisciplinary rehabilitation measures ongoing or planned.

The recruited patients were interviewed by telephone by a research assistant within 2 days. The patients who remained qualified saw the assistant at the health centre within 5 days. Before the assistant carried out the randomization, certain procedures were completed: the patient finished a questionnaire, including a pain drawing; the assistant categorized the pain as being back and/or neck pain, basing the decision on how the patient completed the pain drawing and by a short interview. The back was taken as the area below an imaginary line connecting the lower tips of the shoulder blades, including the lower half of the thoracic spine and the lumbar spine; and the neck was the area on and above this line, including the upper half of the thoracic spine and the cervical spine [10]; the patient also performed a package of 10 function tests as described in detail in a previous study [11].

\section{Design}

This prospective cohort study is a re-assessment of the data from the randomized controlled trial with the 2 treatment groups considered as a single cohort.

\section{Outcome variable}

Stable return-to-work The outcome variable was Stable return-to-work, which required that a return-to-work on a specific day lasted for at least 1 month. For example, a Stable return-to-work on 6 June required that the return-to-work continued at least up to and including 5 July. The reference to Stable return-to-work was Nonreturn-to-work, including non-return-to-work a specific day and return-to-work that day but with recurrence of 
work absence the following month. Due to the responsibility of the employer, Stable return-to-work possibly contained a period of work absence of a maximum of 14 days during the follow-up month including the specific day. Stable return-to-work was analyzed in 4 specific days during a 2-year period, selected as 6, 12, 18 and 24 months after baseline.

\section{Predictive variables}

Objective variables Six reliable function tests from the 10 -test package were used as objective variables. In a previous study, we had examined the reliability, including inter- and intra-rater reliability, of the package [11]. In summary, 2 examiners participated, an experienced physiotherapist and a research assistant. All the 5 tests that did not require manual fixation of the patient by the examiner were reliable. Only 1 of the 5 tests which required fixation was reliable. In conclusion, 6 of the
10 tests were reliable and could be used by an examiner lacking formal medical education (the research assistant) without loss of quality. Two of those tests included flexion to the right and to the left and rotation to the right and to the left, and a lift test comprised a lumbar and a cervical subtest. Nine subtests in total are given in Table 1.

\section{Socioeconomic variables}

These were collected from the questionnaire except data for the 2 sick-listing variables, which were collected from The Social Insurance Office. The sick-listing variables were: Subacute NSP = current, full-time sick-listing at baseline for NSP of 6-12 weeks (42-84 days) with the reference Chronic NSP = current, full-time sick-listing of more than 12 weeks up to and including 2 years (85-730 days) [8], and Low total prior sick-listing $=$ at most 183 net days during the 2 years prior to baseline, including all diagnoses, with the reference High total

Table 1 Objective variables. Results of univariate-logistic regression, adjusted for gender and age, with $p$-values of at most .10

\begin{tabular}{|c|c|c|c|c|c|c|c|c|c|c|c|c|c|c|}
\hline \multirow[b]{3}{*}{ Subtests } & \multirow[b]{3}{*}{ Class limits } & \multirow[b]{3}{*}{$\mathbf{n}$} & \multicolumn{12}{|c|}{ Prediction for Stable return-to-work } \\
\hline & & & \multicolumn{3}{|c|}{6 months } & \multicolumn{3}{|c|}{12 months } & \multicolumn{3}{|c|}{18 months } & \multicolumn{3}{|c|}{24 months } \\
\hline & & & OR & $p$ & $95 \% \mathrm{Cl}$ & OR & $p$ & $95 \% \mathrm{Cl}$ & OR & $p$ & $95 \% \mathrm{Cl}$ & OR & $p$ & $95 \% \mathrm{Cl}$ \\
\hline \multirow[t]{3}{*}{ Forward flexion (centimeters $(\mathrm{cm})$ ) } & $25-64$ & 41 & & & & & & & Ref. & & & Ref. & & \\
\hline & $8-24$ & 42 & - & - & - & - & - & - & 3.4 & .01 & $1.3-8.8$ & 2.6 & .05 & $1.0-6.5$ \\
\hline & $0-7$ & 41 & - & - & - & - & - & - & 2.1 & NS & $.8-5.6$ & 1.3 & NS & $.5-3.2$ \\
\hline \multirow[t]{3}{*}{ Modified Schober (cm) } & $1-3$ & 18 & & & & & & & & & & & & \\
\hline & $4-6$ & 83 & - & - & - & - & - & - & - & - & - & - & - & - \\
\hline & $7-19$ & 23 & - & - & - & - & - & - & - & - & - & - & - & - \\
\hline \multirow[t]{3}{*}{ Lateral flexion right $(\mathrm{cm})$} & $3-10$ & 41 & & & & & & & Ref. & & & & & \\
\hline & $11-15$ & 39 & - & - & - & - & - & - & 2.3 & .09 & $.9-6.2$ & - & - & - \\
\hline & $16-28$ & 44 & - & - & - & - & - & - & 1.9 & NS & $.8-4.9$ & - & - & - \\
\hline \multirow[t]{3}{*}{ Lateral flexion left $(\mathrm{cm})$} & $2-11$ & 41 & & & & & & & Ref. & & & & & \\
\hline & $12-15$ & 38 & - & - & - & - & - & - & 2.9 & .03 & $1.1-7.6$ & - & - & - \\
\hline & $16-27$ & 45 & - & - & - & - & - & - & 1.8 & NS & $.7-4.7$ & - & - & - \\
\hline \multirow[t]{3}{*}{ Cervical rotation right (degrees) } & $0-50$ & 44 & & & & & & & & & & Ref. & & \\
\hline & $51-60$ & 43 & - & - & - & - & - & - & - & - & - & 2.6 & .04 & $1.0-6.6$ \\
\hline & $61-80$ & 37 & - & - & - & - & - & - & - & - & - & 2.7 & .05 & $1.0-7.1$ \\
\hline \multirow[t]{3}{*}{ Cervical rotation left (degrees) } & $0-50$ & 47 & & 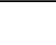 & & & & & & & & & & \\
\hline & $51-60$ & 39 & - & - & - & - & - & - & - & - & - & - & - & - \\
\hline & $61-80$ & 38 & - & - & - & - & - & - & - & - & - & - & - & - \\
\hline \multirow[t]{3}{*}{ Abdominal endurance (seconds) } & 0 & 46 & & 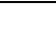 & & & & & & & & & & \\
\hline & $1-14$ & 40 & - & - & - & - & - & - & - & - & - & - & - & - \\
\hline & $15-75$ & 38 & - & - & - & - & - & - & - & - & - & - & - & - \\
\hline \multirow[t]{3}{*}{ PILE lumbar (kilogram) } & $0-6$ & 33 & & & & & & & & & & & & \\
\hline & $8-12$ & 45 & - & - & - & - & - & - & - & - & - & - & - & - \\
\hline & $14-44$ & 46 & - & - & - & - & - & - & - & - & - & - & - & - \\
\hline \multirow[t]{3}{*}{ PILE cervical (kilogram) } & $0-6$ & 37 & Ref. & & & & & & Ref. & & & & & \\
\hline & $8-12$ & 47 & 1.4 & NS & $.5-4.4$ & - & - & - & 1.1 & NS & $.4-2.9$ & - & - & - \\
\hline & $14-44$ & 40 & 2.9 & .09 & $.9-9.5$ & - & - & - & 2.8 & .06 & $1.0-8.4$ & - & - & - \\
\hline
\end{tabular}

$\mathrm{OR}=$ Odds ratio. $95 \% \mathrm{Cl}=95 \%$ confidence interval. Ref. $=$ Reference, which always has OR $=1.0$. NS $=$ Non-significant $(p>.10)$

The rationales for the choice of the function tests were established in a previous study [11]. 
included the answering alternatives 'rather probable',probable' and 'very probable', and Low self prediction the alternatives 'rather improbable', 'improbable' and 'very improbable'. A similar type of question was used by Linton et al. [15], but included a future time-limit of 6 months, i.e. a much shorter period than our 2-year follow-up. We therefore chose the open-ended question from Eklund et al. [14]. A total of 16 subjective variables are shown in Table 3.

\section{Treatment variables}

Sixty-three of the 125 patients received Cognitive-behavioural rehabilitation and 62 patients received the reference treatment of Traditional primary care. The treatment options were described in detail in a previous study [9].

\section{Statistics}

STATA10.1 was used for the calculations [16].

\section{Table 3 Subjective variables}

\begin{tabular}{|c|c|c|c|c|c|c|c|c|c|c|c|c|c|c|}
\hline & \multirow[b]{3}{*}{ Class limits } & \multirow[b]{3}{*}{$\mathbf{n}$} & \multicolumn{12}{|c|}{ Prediction for Stable return-to-work } \\
\hline & & & \multicolumn{3}{|c|}{6 months } & \multicolumn{3}{|c|}{12 months } & \multicolumn{3}{|c|}{18 months } & \multicolumn{3}{|c|}{24 months } \\
\hline & & & OR & $p$ & $95 \% \mathrm{Cl}$ & OR & $p$ & $95 \% \mathrm{Cl}$ & OR & $p$ & $95 \% \mathrm{Cl}$ & OR & $p$ & $95 \% \mathrm{Cl}$ \\
\hline \multirow[t]{3}{*}{ Pain just now (VAS 1-100)[25] } & $70-100$ & 41 & Ref. & & & & & & & & & & & \\
\hline & $48-69$ & 43 & 2.4 & .09 & $.9-6.9$ & - & - & - & - & - & - & - & - & - \\
\hline & $0-47$ & 40 & 1.5 & NS & $.5-4.3$ & - & - & - & - & - & - & - & - & - \\
\hline \multirow[t]{3}{*}{ Pain at worst last week[25] } & $81-100$ & 42 & Ref. & & & & & & & & & & & \\
\hline & $68-80$ & 43 & 2.5 & .09 & $.9-6.8$ & - & - & - & - & - & - & - & - & - \\
\hline & $0-67$ & 39 & 1.4 & NS & $.5-4.2$ & - & - & - & - & - & - & - & - & - \\
\hline Intermittent pain[15] ${ }^{1}$ & - & 39 & - & - & - & - & - & - & 2.3 & .04 & $1.0-5.4$ & - & - & - \\
\hline Non-radiating pain $[17]^{2}$ & - & 32 & - & - & - & - & - & - & - & - & - & - & - & - \\
\hline Local pain $[25]^{3}$ & - & 24 & - & - & - & - & - & - & - & - & - & - & - & - \\
\hline Back-pain domination[32] ${ }^{4}$ & - & 86 & 9.0 & .004 & $2.0-40.2$ & 2.5 & .05 & $1.0-6.4$ & - & - & - & - & - & - \\
\hline \multirow[t]{3}{*}{ Time since start of NSP (years)[27] } & $>5$ & 53 & & & & & & & Ref. & & & Ref. & & \\
\hline & $1.5-5$ & 34 & - & - & - & - & - & - & 2.9 & .03 & $1.1-7.4$ & 2.2 & .09 & $.9-5.5$ \\
\hline & $<1.5$ & 37 & - & - & - & - & - & - & 1.5 & NS & $.6-3.6$ & 1.1 & NS & $.5-2.7$ \\
\hline No surgery $f . b / n$ pain $[50]^{5}$ & - & 116 & - & - & - & - & - & - & - & - & - & - & - & - \\
\hline No anxiety/depression[15] ${ }^{6}$ & - & 26 & - & - & - & - & - & - & - & - & - & - & - & - \\
\hline Tired seldom[67] $]^{7}$ & - & 59 & 3.1 & .01 & $1.3-7.6$ & - & - & - & 1.9 & .09 & $.9-4.2$ & - & - & - \\
\hline No comorbidity[68] ${ }^{8}$ & - & 79 & - & - & - & - & - & - & - & - & - & - & - & - \\
\hline Non-severe functional impairment (ODI) ${ }^{9}$ & - & 78 & 2.1 & .09 & $9-4.9$ & 2.9 & .01 & $1.3-6.8$ & 2.5 & .02 & $1.2-5.4$ & - & - & - \\
\hline Health-related & $0-.359$ & 42 & Ref. & & & Ref. & & & Ref. & & & & & \\
\hline quality of life & $.360-.629$ & 46 & 2.8 & .06 & $1.0-8.3$ & 2.1 & NS & $.8-5.4$ & 2.1 & NS & $.8-5.1$ & - & - & - \\
\hline$(E Q-5 D)[21]$ & $.630-1.0$ & 36 & 2.9 & .06 & $.9-8.9$ & 2.6 & .06 & $1.0-7.1$ & 3.0 & .03 & $1.1-7.9$ & - & - & - \\
\hline \multirow[t]{3}{*}{ State of health (EQ-VAS)[21] } & $0-35$ & 44 & Ref. & & & . & & & Ref. & & & & & \\
\hline & $36-49$ & 33 & 2.2 & NS & $.7-7.0$ & - & - & - & 2.0 & NS & $.7-5.4$ & - & - & - \\
\hline & $50-100$ & 47 & 3.6 & .02 & $1.3-10.3$ & - & - & - & 3.1 & .01 & $1.3-7.7$ & - & - & - \\
\hline Non-catastrophizing[70] $^{10}$ & - & 67 & 2.2 & .08 & $9-5.1$ & - & - & - & 3.6 & .002 & $1.6-8.0$ & 2.3 & .04 & $1.1-4.9$ \\
\hline High self prediction[14] & - & 95 & 4.2 & .03 & $1.2-15.2$ & 6.4 & .002 & $1.9-21.0$ & 4.4 & .005 & $1.5-12.4$ & 3.8 & .008 & $1.4-10.2$ \\
\hline \multicolumn{15}{|c|}{${ }^{1}$ Reference: Continual pain = pain whenever awake $(n=95)$. } \\
\hline \multicolumn{15}{|c|}{${ }^{2}$ Reference: Radiating pain = radiation of pain/numbness to the leg beneath the knee and/or the arm beneath the elbow $(n=92)$. } \\
\hline \multicolumn{15}{|c|}{${ }^{3}$ Pain in the back or the neck. Reference: Widespread pain $=$ pain in both the back and the neck $(n=100)$} \\
\hline \multicolumn{15}{|l|}{${ }^{4}$ Reference: Neck-pain domination $(n=38)}$. \\
\hline \multicolumn{15}{|c|}{${ }^{5}$ Reference: Surgery for back and/or neck pain at least once (for example, for a slipped disc) ( $n=8$ ). } \\
\hline \multicolumn{15}{|c|}{${ }^{6}$ Item 5 in EQ-5 D[20], alternative 1 = "I am not anxious or depressed". Reference: alternative 2: "... moderately..." or 3: "... extremely...". } \\
\hline \multicolumn{15}{|c|}{$\begin{array}{l}7 \text { One item from SF 36[67]: 'Tired during the last four weeks: 'some of the time', 'a little bit of the time' or 'none of the time'". Reference: Tired often = 'all of the } \\
\text { time', 'most of the time' or 'a good bit of the time'. }\end{array}$} \\
\hline \multicolumn{15}{|c|}{${ }^{8}$ Reference: Comorbidity $=$ any other, chronic disease except NSP or obesity $(n=45)$} \\
\hline \multicolumn{15}{|c|}{$\begin{array}{l}{ }^{9} \mathrm{ODI}(\text { Oswestry Disability Index) scores general functional disability associated with back pain, } 0-100 \%: 0-20 \%=\text { minimal, } 21-40 \%=\text { moderate, } 41-60 \%=\text { severe, } \\
61-100 \%=\text { extremely severe to crippling disability[38]. Reference: Non-severe functional impairment }=\mathrm{ODI}<41 \%[69]\end{array}$} \\
\hline${ }^{10}$ Six catastrophizing thoughts, never-alway & $50-6$, are summ & & & & & & & ence: Catas & & & $15(n=39$ & & & \\
\hline
\end{tabular}




\section{Power calculation}

The power calculation of the randomized controlled trial has been described in a previous study [9]. In this prospective cohort study we were reduced to analyze the number of patients who were already included in the randomized controlled trial. However, several prior prediction studies included a comparable number of patients, e.g. Eklund et al. [14] 149 patients, Lancourt et al. [17] 134 patients, and Linton et al. [15] 142 patients.

\section{Stable return-to-work}

Stable return-to-work for 6, 12, 18 and 24 months, and of disability pension in 24 months were calculated. The proportions were compared between the genders by univariate-logistic regression, adjusted for age (Young age = 18-44 years and Older age $=45-59$ years) and are given with $p$-values [18]. In the logistic regression Stable return-to-work might have the values 1 , including the degrees .25, .50, .75 and 1.00, or $0=$ Non-return-to-work.

\section{Multiple-logistic regression}

We built 4 multiple-logistic regression models for each of the follow-ups at 6,12, 18 and 24 months. The outcome variable was Stable return-to-work. The predictive variables were the above described objective, socioeconomic, subjective and treatment variables. Ordinal and continuous variables were divided into classes. The models were adjusted for gender and age. We first explored univariate analyses. The variables with a $p$-value of at most .10 are presented with odds ratios (OR), $p$-values and 95\% confidence intervals (CI). They were included in a multiple model, from which the variables with $p$-values of .05 or higher were excluded stepwise to yield a model comprising only variables with $p$-values $<.05$. However, in the choice between a model with a larger number of variables including those with $p$-values of .05 or slightly above and a smaller model with $p$-values exclusively smaller than .05 , the larger model was tested against the smaller model (STATA commandos "estimates store full" and "lrtest full"). If that test produced a $p$-value smaller than .05 , the larger model was chosen as the ultimate one, otherwise the smaller model [18]. All possible first-order interaction terms were tested in each model.
Although it is important that a multiple-logistic regression model includes all relevant predictor variables, it is also important that the model does not include more predictors than the given number of observations justify. The existence of sufficient events per variable was emphasized by Bagley et al. [19] in a large overview of logistic regression. The number of the less common of 2 possible outcomes (in our study Stable return-to-work or Non-return-to-work) divided by the number of predictor variables was recommended to be at least 10 and preferably more [20]. On the basis of the number of patients with Stable return-to-work (Table 4), the maximal possible numbers of predictors were calculated as 3,5,5-6 and 6 at 6, 12, 18 and 24 months, respectively. While the models of 18 and 24 months lived up to that with 5 and 4 variables each, the models of 6 and 12 months included 5 and 6 variables, which necessitated the exclusion of 2 and 1 predictors respectively. We excluded from the 6-month model No vibrations, OR 5.9 [1.7-20.8](95\% CI), $p=$ .006 , since this variable was represented in only one of the other follow-ups; and Tired seldom, OR 3.3 [1.2-9.4], $p=.02$, since it was not found in other follow-ups. From the 12-month model No vibrations, OR 3.2 [1.19.3], $p=.03$, was excluded, since it was found in only one of the other follow-ups. By the exclusion of $\mathrm{No}$ vibrations one of the remaining variables, Man, became non-significant ( $p$ changed from .02 to .08), and was left outside the final presentation of the 12-month model. Like No vibrations, Back-pain domination was represented in only the 6- and 12-month follow-ups, but was retained in the models due to its outstanding OR in 6 months. The results of the final models are shown as OR with $p$-values and 95\% CI with goodness-of-fit tests by Hosmer-Lemeshow, the percentages of correctly predicted patients and the areas under ROC-curves [18].

We found no comparable studies of return-to-work at several time-points; for example, Hansson et al. [21] analyzed return-to-work at 90 days, 12 and 24 months, but their study included $\sim 1500$ subjects and no objective variables. However, we appraised that the comparatively small number of cases in our study made it risky to associate certain predictors with certain time-points. We chose to

Table 4 Stable return-to-work

\begin{tabular}{|c|c|c|c|c|c|c|c|c|c|c|c|c|}
\hline & \multicolumn{3}{|c|}{6 months } & \multicolumn{3}{|c|}{12 months } & \multicolumn{3}{|c|}{18 months } & \multicolumn{3}{|c|}{24 months } \\
\hline & $n$ & $\begin{array}{l}\text { Stable return-to-work } \\
\mathrm{n}(\%)\end{array}$ & $p$ & $n$ & $\begin{array}{l}\text { Stable return-to-work } \\
\text { n (\%) }\end{array}$ & $p$ & $n$ & $\begin{array}{l}\text { Stable return-to-work } \\
\mathrm{n}(\%)\end{array}$ & $p$ & $n$ & $\begin{array}{l}\text { Stable return-to-work } \\
\mathrm{n}(\%)\end{array}$ & $p$ \\
\hline All & 124 & 33 (26.6) & - & 123 & 48 (39.0) & - & 122 & $55(45.1)$ & - & 122 & $58(47.5)$ & - \\
\hline Men & 56 & 19 (33.9) & NS & 55 & $27(49.1)$ & NS & 54 & $29(53.7)$ & NS & 54 & $30(55.6)$ & NS \\
\hline Women & 68 & $14(20.6)$ & NS & 68 & $21(30.9)$ & NS & $\overline{68}$ & $26(38.2)$ & NS & 68 & $28(41.2)$ & NS \\
\hline
\end{tabular}

NS = Non-significant $(p \geq .05)$.

All patients and gender. The proportions are compared by univariate logistic regression, adjusted for age. 
take into final consideration only the variables that were represented in at least 3 of the 4 follow-ups.

\section{Ethical approval}

Approval for the study was given by The Research Ethics Committee, Karolinska University Hospital, Huddinge.

\section{Results}

A flow-chart of the study is shown in Figure 1.

\section{Source population}

From data in a cross-sectional study under preparation, the point prevalence of severe spinal pain in the source

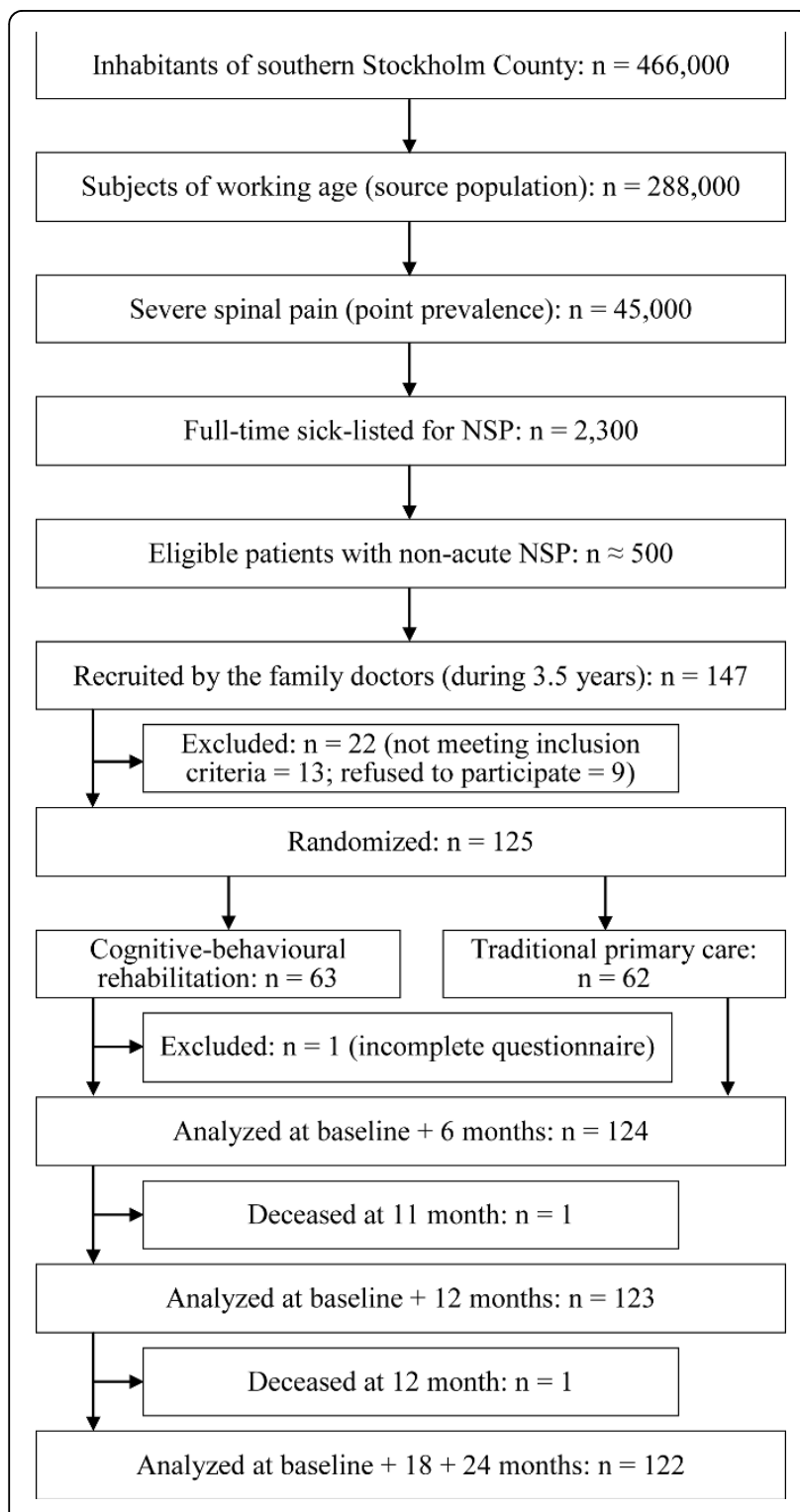

Figure 1 Flowchart. Further explanation can be found in the text. population was estimated at $15.6 \%$ or $\sim 45,000$ subjects, and of full-time sick-listing due to spinal pain to $.8 \%$ or $\sim 2,300$ subjects, including short- and long-term sick-listing. The data were collected from Statistics Sweden, a governmental authority [22]. The great majority of patients with disabling NSP recovers quickly. Roughly, after full-time sick-listing 1 week around $50 \%$ and after 12 weeks $90 \%$ of the patients have returned to work. Thereafter the recovering speed evidently levels off [8]. We estimated the point prevalence of non-acute NSP in the source population to around .2\% or 500 subjects. We have no data of the prevalence over time.

\section{Loss to follow-up}

Three of the 125 patients, all males, deceased during the follow-up, 11, 12 and 22 months after baseline. The last deceased patient was excluded from the study because of an incomplete questionnaire. The other 2 subjects were analyzed up to their possible follow-ups. The questionnaires of 124 patients were analyzed and sick-listing data were collected at $6,12,18$ and 24 months for 124 , 123,122 and 122 patients, respectively.

\section{Study population}

Of the 124 patients, Subacute NSP and Chronic NSP occurred in $38(30.6 \%)$ and $86(69.4 \%)$ patients, respectively. The current sick-listing period at baseline was $m$ 172 [149-194], days. Back-pain domination and Neckpain domination was seen in 86 (69.4\%) and 38 (30.6\%) patients, respectively. Twenty-four patients (19.4\%) had Local pain, i.e. back or neck pain, and 100 patients (80.6\%) had Widespread pain, i.e. both back and neck pain.

\section{Stable return-to-work}

Stable return-to-work gradually increased and was 58/ $122(47.5 \%)$ at 24 months, a majority at full-time (43/58 $=74.1 \%)$. The proportions were generally higher for men, but the gender differences were non-significant (Table 4). At 24 months, disability pension (temporary or permanent) was received by 30/122 (22 full- and 8 half-time pensions), with a significantly higher proportion of women, $22 / 68(32.4 \%)$, than men, $8 / 54$ (14.8\%) $(p=.04)$.

\section{Predictors of Stable return-to-work}

In the univariate analyses, several objective, socioeconomic and subjective variables were associated with Stable return-to-work (Tables 1, 2, 3, while the treatment variables, Cognitive-behavioural rehabilitation or Traditional primary care, were not predictive in any of the follow-ups.

In the multiple-logistic models only socioeconomic and subjective variables remained, of which 3 variables were finally considered, all of them represented in 
3 follow-ups (Table 5): Low total prior sick-listing, including all diagnoses, was the strongest predictor in 2 follow-ups, and High self prediction and Young age were the strongest and second strongest, respectively, in one of the follow-ups. In the models there were 3, 6, 10 and 10 first-order interaction terms, respectively, but none was predictive. The model fit was generally good and the proportions of correctly classified patients were satisfactory (on average $74.1 \%$ ).

\section{Discussion}

The predictors of stable return-to-work were analyzed in 124 patients with non-acute NSP. Of the total of 50 variables, 2 socioeconomic variables, Low total prior sick-listing and Young age, and 1 subjective variable, High self prediction, were finally considered. None of the objective variables from function tests and of the treatment variables were predictive.

\section{Predictors in the study compared with prior research}

Young age is in line with several previous studies and reviews [1,23-27]. Also High self prediction is a well known predictor $[14,15,28,29]$. For example, the basic question in the clinical algorithm for return-to-work prediction by Dionne et al. [28] concerned the patient's own recovery expectations.

One of the most consistent predictors in previous research was low prior sick-listing for spinal pain $[26,30,31]$. While Subacute NSP was one of the strongest predictors in the univariate analyses, it was outflanked in the multiple context by Low total prior sick-listing, except at 6 months. According to one of the hitherto most extensive reviews of predictors of long-term sicklisting for spinal pain, prior sick-listing for all diagnoses has been insufficiently studied [1]. Our results indicate that it is very important to map prior sick-listing for all diagnoses, not only for spinal pain. This is also in line with the Örebro Musculoskeletal Pain Questionnaire, a widely-used screening instrument [15], and with fairly recent studies with prolonged follow-ups [12,32].

Non-predictors in the study compared with prior research Two non-predictors were in line with previous studies, Comfortable work postures [26,30] and Good social support $[25,26]$. Non-Smoking as a non-predictor is supported by some studies [33,34], but is contradicted by others: a large review of mostly cross-sectional studies indicated a possible association between NSP and cigarette smoking, but emphasized the lack of prospective studies [35]. Recent, prospective studies pinpointed cigarette smoking as a strong predictor of non-returnto-work in men, Dionne et al. [5], and as a moderate predictor of non-return in both sexes, Stillgate et al. [36].

Six of our non-predictors contradicted prior research:

Man and Non-low education were non-predictors, while prior research indicated them as predictors, at least for disability pension $[1,12]$. However, the proportion of disability pension at 24 months was significantly lower for men and Non-low education was close to qualify with a representation at both 18 and 24 months. It is logical that a disability pension will be granted only after prolonged sick-listing and that education might influence return-to-work comparatively late in a rehabilitation process, when the medical efforts have been replaced by vocational measures. Consequently, our findings might be in line with prior research, although a longer follow-up than 2 years is required to confirm this.

High physical workload, the reference to Light physical workload, is a well-established predictor of low returnto-work $[26,30,34,37]$, but was non-predictive in our

Table 5 Predictors of Stable return-to-work

\begin{tabular}{|c|c|c|c|c|c|c|c|c|c|c|c|c|}
\hline \multirow{3}{*}{6 months } & \multicolumn{12}{|c|}{ Prediction for Stable return-to-work } \\
\hline & \multicolumn{5}{|c|}{12 months } & \multicolumn{3}{|c|}{18 months } & \multicolumn{3}{|c|}{24 months } & \multirow[b]{2}{*}{$95 \% \mathrm{Cl}$} \\
\hline & OR & $p$ & $95 \% \mathrm{Cl}$ & OR & $p$ & $95 \% \mathrm{Cl}$ & OR & $p$ & $95 \% \mathrm{Cl}$ & OR & $p$ & \\
\hline Young age & - & - & - & 2.8 & .02 & $1.2-6.5$ & 3.5 & .001 & $1.3-9.1$ & 2.7 & .02 & $1.2-6.2$ \\
\hline Non-low education & - & - & - & - & - & - & 3.0 & .04 & $1.1-8.2$ & 2.9 & .02 & $1.2-6.9$ \\
\hline Subacute NSP & 3.2 & .02 & $1.3-8.2$ & - & - & - & 3.0 & .04 & $1.1-8.4$ & - & - & - \\
\hline Low total prior sick-listing & - & - & - & 2.7 & .02 & $1.2-6.4$ & 4.8 & .001 & $1.9-12.3$ & 3.8 & .002 & $1.6-8.7$ \\
\hline Back-pain domination & 9.5 & .004 & $2.0-44.4$ & 2.9 & .04 & $1.1-7.7$ & - & - & - & - & - & - \\
\hline Non-catastrophizing & - & - & - & - & - & & 3.4 & .01 & $1.3-9.1$ & - & - & - \\
\hline High self prediction & 4.1 & .02 & $1.1-15.7$ & 5.2 & .009 & $1.5-17.5$ & - & - & - & 2.7 & .06 & $.9-7.8$ \\
\hline \multicolumn{13}{|l|}{ Goodness-of-fit: } \\
\hline Hosmer-Lemeshow & \multicolumn{3}{|c|}{.70} & \multicolumn{3}{|c|}{.38} & \multicolumn{3}{|c|}{.29} & \multicolumn{3}{|c|}{.67} \\
\hline Correctly classified (\%) & \multicolumn{3}{|c|}{78.2} & \multicolumn{3}{|c|}{71.5} & \multicolumn{3}{|c|}{73.0} & \multicolumn{3}{|c|}{73.8} \\
\hline Area under ROC & \multicolumn{3}{|c|}{.79} & \multicolumn{3}{|c|}{.79} & \multicolumn{3}{|c|}{.85} & \multicolumn{3}{|c|}{.79} \\
\hline
\end{tabular}

Multiple-logistic regression. The variables found in at least three follow-ups are in bold text. 
study. The large majority of our patients (83.2\%) had a High physical workload (compared to $15.4 \%$ of a population-based local sample in a cross-sectional study in preparation [22]). Thus, a variable of such overwhelming frequency might be non-discriminative, although it has a powerful effect on sick-listing.

Non-severe functional impairment, as measured by the Oswestry Disability Index [38-40], Health-related quality of life, according to EQ-5 D [21,41], and State of health, as expressed by EQ VAS [21], were comparatively strong predictors in the univariate analyses, but non-predictors in the final multiple-logistic models. This is contrary to previous studies [5,21,25,38-40], for which we can offer no explanation.

\section{Non-predictors in the study that have previously been insufficiently studied}

Many of our non-predictors that have been insufficiently studied in previous research might contribute to a widening of knowledge: Non-immigrant, Co-habiting, Living without children, Non-unemployment, No work trauma litigation, Non-bad economy, Non-obese, No comorbidity, No surgery for spinal pain, Pain duration, Pain intensity, Local pain, Back-pain domination, High physical activity, Varied work moments, No job strain, No depression/anxiety and No indications of alcohol over-consumption [1].

Concerning pain localisation and alcohol, prior studies are conflicting: While the predictive value of spinal pain localization has been questioned $[1,15]$, recent research, including very large samples, supports the positive effect on return-to-work of Back-versus Neck-pain domination [21,32]. Back-pain domination in our study was near to qualify with a strong representation in 2 followups. So, the non-prediction might be due to the comparatively low number of patients. While one study showed no association between alcohol over-consumption and sick-listing for spinal pain [41], another study found that alcohol abuse was higher among persons with chronic spinal pain [42]. A recent large study indicated that moderate alcohol consumption tended to decrease sick-listing for NSP, at least among women in the public sector [36].

\section{Objective versus subjective variables}

As few of the function tests commonly used in previous research were validated, it is difficult to judge from prior studies if objective variables are predictive [6]. For example, in a Cochrane review of specific spinal pain, subjective variables such as the state of health predicted return-to-work, but there was insufficient scientific support concerning objective variables, such as strength or motion range [7]. Our study strongly supports the predictive value of subjective predictors and might widen the knowledge of objective variables as nonpredictors.

\section{Treatment as a predictor of return-to-work}

For the entire group of patients, treatment was non-predictive. In a previous study [9], there were indications that patients with Subacute NSP had a greater returnto-work chance when they received the cognitive-behavioural programme. However, a more detailed evaluation of the possible positive effect on return-to-work of our programme requires other analyses than in the present study - for example, survival analysis as in the previous study [9] - and is a matter for future work.

\section{Strengths of the study}

The prospective design, with a comparatively long follow-up period, is a major strength of our study.

The generalisation of the results of previous research on the prediction of return-to-work in spinal pain is seriously limited by the under-representation of women [1] Thus one strength of our study has been the good representation of women.

We have no data of the proportion of work obstacles due to back pain compared with neck pain in the source population. In previous research, the annual prevalence in industrial countries of work obstacles due to back pain and neck pain has been estimated to $8 \%$ and $2 \%$, respectively [43]. We obtained a similar ratio, which might indicate that our study sample is representative of subjects with non-acute NSP.

Because we used data from the Social Insurance Office, no sick-listing data was missing, except the possible short-term relapses of non-return-to-work during the follow-up months. With the exclusion of one patient, the questionnaire data were complete.

The use of reliable function tests is a major strength. One of the examiners in our reliability study [11], the research assistant, also carried out the function tests in this study.

\section{Limitations of the study}

Some circumstances might have decreased the representativeness of the study sample, and increased the risk of bias. The above-mentioned annual prevalence of work limiting back pain and neck pain corresponds to $\sim 23,000$ and $\sim 5,000$, respectively, in the source population. Though these data include short-term sick-listing also, it is obvious that the study population of 125 patients recruited over a period of 3.5 years constituted a very low percentage of the eligible subjects. As a comparison, Dionne et al al. [28] achieved a participation rate of $68.4 \%$ of eligible subjects. The inclusion was 
non-systematic: a family doctor with a local reputation of great skills in spinal pain might attract more complex cases, and have a higher motivation for research and the recruitment of study patients. This might lead to spectrum bias, i.e. the effect the patient mix may have on the performance of tests, e.g., a package of predictors [44]. We were overoptimistic concerning the recruiting propensity of the family doctors and lacked resources to make them more compliant. This contributed to a prolonged inclusion period ( 3.5 years) that increased the probability of societal changes in rules and attitudes concerning sick-listing and might result in different return-to-work predictors in identical spinal pain due to inclusion either early or late in the recruitment period. The problem with protracted inclusion periods is shared with several other studies. For example, Lindström et al. [45] and Loisel et al. [46] used 2.5 years for the inclusion of 103 and 130 patients, respectively, and Jensen et al. [47] 3.5 years for 214 patients. As a comparison, Dionne et al. [28] used a systematic approach and recruited 1007 patients in about 1.5 years.

While it is advocated that predictive conclusions might be drawn exclusively from studies with a sick-listing-baseline on day zero [48], our patients had been sick-listed for at least 6 weeks at baseline, which might be seen as a limitation. However, even in the abovementioned large review [1], several of the studies had baselines similar to ours $[17,26,34]$ and arguably it is also of great interest to predict return-to-work in nonacute NSP.

Work satisfaction as a separate variable was not included. Since work satisfaction was indicated as a return-to-work predictor in several previous studies $[25,49,50]$, it is a limitation.

There is no gold standard enabling the analysis of the time-points of return-to-work [51], but logically different predictors have a different impact in different timepoints. While education might have a stronger influence comparatively late, pain and other subjective variables might affect the outcome early. It is also of great interest to know what variables predict return-to-work and when. For example, prediction of return-to-work, but not until 24 months, might be of no use concerning a patient close to old-age pension. A limitation of our study is that the follow-ups are not mutually compared, which should require a larger number of cases.

As cognitive-behavioural therapy, among other items, addresses dysfunctional beliefs [52], Cognitive-behavioural rehabilitation given to half of the patients might have a greater impact on the self prediction and result in an underestimation in the association between High self prediction and return-to-work. This might be a limitation of the study. However, as none of the treatment variables predicted Return-to-work, we consider the potential bias achieved by the treatment as negligible.

\section{Conclusions}

In primary-care patients with non-acute, non-specific spinal pain, including back and/or neck pain, the strong predictors of stable return-to-work were 2 socioeconomic variables, Low total previous sick-listing (including all diagnoses) and Young age ( $\max 44$ years), and 1 subjective variable, High self prediction (the patients' own belief in return-to-work). Objective variables from function tests and treatment variables (a programme of cognitive-behavioural rehabilitation or traditional primary care) were non-predictors. Except for Young age, the predictors had been insufficiently studied in previous research. Hence, our study might contribute to a widening of knowledge within clinical practice, including the allocation of treatment resources.

\section{Acknowledgements}

This study was supported by grants from the Stockholm County Social Insurance Agency, Stockholm County Council, Ministry of Health and Social Affairs, Vårdal Foundation, Cardionics, Pharmacia (now part of Pfizer) and Grunenthal Sweden AB.

\section{Authors' contributions}

$\mathrm{OL}$ was the main investigator, carried out the study, performed the analysis and drafted the manuscript. SEJ contributed to the statistical analysis. LES, as supervisor of $\mathrm{OL}$, participated in all phases of the study. All authors read and approved the final manuscript.

\section{Competing interests}

The authors declare that they have no competing interests.

Received: 18 December 2009 Accepted: 20 July 2010

Published: 20 July 2010

\section{References}

1. Hansson T, Jensen I: Sickness absence due to back and neck disorders. sickness absence - causes, consequences, and physicians' sickness-certification practice Scand J Public HealthAlexanderson K, Norlund A 2004, 32(Suppl 63):109-151.

2. Newly awarded disability pensions. Distribution between counties and diagnoses, 2006. [Swedish; Nybeviljade sjukersättningar/aktivitetsersättningar. Fördelning på län och diagnos, 2006] Social Insurance in Sweden. Statistics 2007, 7 [http://statistik.forsakringskassan.se/rfvexcel/statpub/ Statistik_2007-02.pdf], [In Swedish; Försäkringskassan. Statistik 2007:7].

3. Key trends and outcomes. Sickness, Disability and Work. Keeping on track in the economic downturn OECD, Directorate for employment, labour and social affairs, Background paper: High-Level Forum, Stockholm 2009 [http:// www.oecd.org/dataoecd/42/15/42699911.pdf].

4. Waddell G, van Tulder M: Clinical guidelines. Back Pain Revolution Edinburgh: Churchill LivingstoneWaddell G, 2 2004, 283-322.

5. Dionne CE, Bourbonnais R, Frémont $P$, Rossignol M, Stock SR, Nouwen A, Larocque I, Demers E: Determinants of "return to work in good health" among workers with back pain who consult in primary care settings: a 2-year prospective study. Eur Spine J 2007, 16:641-655.

6. Ljungquist T: Physical performance tests and spinal pain. Assessing impairments and activity limitations. PhD thesis Division of Physiotherapy, Neurotec Department, and Section for Personal Injury Prevention, Department of Clinical Neuroscience, Karolinska Institutet, Stockholm, Sweden 2002.

7. Ostelo RW, de Ver HC, Waddell G, Kerckhoffs MR, Leffers P, van Tulder M: Rehabilitation following first-time lumbar disc surgery: a systematic 
review within the framework of the Cochrane collaboration. Spine 2003, 28:209-218.

8. Waddell G: The biopsychosocial model. Back Pain Revolution Edinburgh: Churchill LivingstoneWaddell G, 2 2004, 265-282.

9. Lindell O, Johansson SE, Strender LE: Subacute and chronic, non-specific back and neck pain: cognitive-behavioural rehabilitation versus primary care. A randomized controlled trial. BMC Musculoskelet Disord 2008, 9:172

10. Platzer W: Color Atlas and Textbook of Human Anatomy. Locomotor system Georg Thieme Verlag Stuttgart 1978, 1:141.

11. Lindell O, Eriksson L, Strender LE: The reliability of a 10-test package for patients with prolonged back and neck pain: Could an examiner without formal medical education be used without loss of quality? A methodological study. BMC Musculoskel Disord 2007, 8:31.

12. Borg K, Hensing G, Alexandersson K: Predictive factors for disability pension - an 11-year follow up of young persons on sick leave due to neck, shoulder or back diagnoses. Scand I Public Health 2001, 29:104-112

13. Arrelöv B, Borgquist L, Ljungberg D, Svärdsudd K: Do GPs sick-list patients to a lesser extent than other physician categories? A population-based study. Fam Pract 2001, 18:393-398.

14. Eklund M, Fugl-Meyer AR: Vocational rehabilitation in northern Sweden. II. Some psycho-socio-demographic predictors. Scand J Rehab Med 1991, 23:73-82.

15. Linton SJ, Halldén K: Can we screen for problematic back pain? A screening questionnaire for predicting outcome in acute and subacute back pain. Clin J Pain 1998, 14:209-215.

16. StataCorp: Stata Statistical Software: Release 9 College Station, TX: StataCorp LP 2005

17. Lancourt J, Kettelhut M: Predicting return to work for lower back pain patients receiving worker's compensation. Spine 1992, 17:629-640.

18. Hosmer DW, Lemeshow S: Applied logistic regression New York: John Wiley \& Sons, 22000.

19. Bagley SC, White H, Golomb BA: Logistic regression in the medical litterature: Standard for use and reporting, with particular attention to one medical domain. J Clin Epidemiol 2001, 54:979-985.

20. Peduzzi P, Concato J, Kemper E, Holford TR, Feinstein AR: A simulation study of the number of events per variable in logistic regression analysis. J Clin Epidemiol 1996, 49:1373-1379.

21. Hansson $E$, Hansson $T$, Jonsson R: Predictors for work ability and disability in men and women with low-back or neck problems. Eur Spine J 2006, 15:780-793.

22. Living conditions. Appendix 16. The Swedish Survey of Living Conditions. Design and methods Official Statistics of Sweden. Statistics Sweden [http:// www.scb.se/statistik/LE/LE0101/_dokument/Appendix_16.PDF].

23. Oleinick A, Gluck JV, Guire K: Factors affecting first return to work following a compensable occupational injury. Am J Ind Med 1996, 30:540-555.

24. Hagen $\mathrm{KB}$, Holte $\mathrm{HH}$, Tambs $\mathrm{K}$, Bjerkedal T: Socioeconomic factors and disability retirement from back pain: a 1983-1993 population-based prospective study in Norway. Spine 2000, 25:2480-2487.

25. van der Giezen AM, Bouter LM, Nijhuis FJ: Prediction of return-to-work of low back pain patients sicklisted for 3-4 months. Pain 2000, 87:285-294.

26. Krause N, Dasinger LK, Deegan LJ, Rudolph L, Brand RJ: Psychosocial job factors and return-to-work after compensated low back injury: a disability phase-specific analysis. Am J Ind Med 2001, 40:374-392.

27. Karlsson N, Borg K, Carstensen J, Hensing G, Alexanderson K: Risk of disability pension in relation to gender and age in a Swedish county; a 12-year population based, prospective cohort study. Work 2006, 27:173-179.

28. Dionne $C E$, Bourbonnais $R$, Frémont $P$, Rossignol M, Stock $S R$, Larocque I: A clinical return-to-work rule for patients with back pain. CMAJ 2005, 172:1559-1567.

29. Du Bois M, Szpalski M, Donceel P: Patients at risk for long-term sick leave because of low back pain. Spine 2009, 9:350-359.

30. Dasinger LK, Krause N, Deegan L, Brand RJ, Rudolph L: Physical workplace factors and return to work after compensated low back injury: a disability phase-specific analysis. J Occup Environ Med 2000, 42:323-333.

31. Waddell G, Burton $\mathrm{K}$ : Occupational heath guidelines for the management of low back pain at work: evidence review. Occup Med 2001, 51:124-135.

32. Bergström $G$, Bodin $L$, Bertilsson $H$, Jensen IB: Risk factors for new episodes of sick leave due to neck or back pain in a working population. A prospective study with an 18-month and a three-year follow-up. J Occup Environ Med 2007, 64:279-287.

33. Boshuizen HC, Verbeek JH, Broersen JP, Weel AN: Do smokers get more back pain? Spine 1993, 18:35-40.

34. Hansson TH, Hansson EK: The effects of common medical interventions on pain, back function, and work resumption in patients with chronic low back pain: A prospective 2-year cohort study in six countries. Spine 2000, 25:3055-3064.

35. Goldberg MS, Scott SC, Mayo NE: A review of the association between cigarette smoking and the development of nonspecific back pain and related outcomes. Spine 2000, 25:995-1014.

36. Skillgate $E$, Vingård $E$, Josephson $M$, Holm LW, Alfredsson L: Is smoking and alcohol consumption associated with long-term sick leave due to unspecific back or neck pain among employees in the public sector? Results of a three-year follow-up cohort study. J Rehabil Med 2009, 41:550-556.

37. Fransen M, Woodward M, Norton R, Coggan C, Dawe M, Sheridan N: Risk factors associated with the transition from acute to chronic occupational back pain. Spine 2002, 27:92-98.

38. Fairbank JC, Couper J, Davies JB, O'Brien JP: The Oswestry low back pain disability questionnaire. Physiotherapy 1980, 66:271-273.

39. Fairbank JC, Pynsent PB: The Oswestry disability index. Spine 2000, 25:2940-2953.

40. Du Bois M, Szpalski M, Donceel P: Patients at risk for long-term sick leave because of low back pain. Spine 2009, 9:350-359.

41. Holmberg SA, Thelin AG: Primary care consultation, hospital admission, sick leave and disability pension owing to neck and low back pain: a 12 -year prospective cohort study in a rural population. BMC Musculoskelet Disord 2006, 7:66.

42. Demyttenaere K, Bruffaerts R, Lee S, Posada-Villa J, Kovess V, Angermeyer MC, Levinson D, de Girolamo G, Nakane H, Mneimneh Z, Lara C, de Graaf R, Scott KM, Gureje O, Stein DJ, Haro JM, Bromet EJ, Kessler RC, Alonso J, Von Korff M: Mental disorders among persons with chronic back or neck pain: results from the World Mental Health Surveys. Pain 2007, 129:332-342.

43. Manchikanti L, Singh V, Datta S, Cohen SP, Hirsch JA: Comprehensive review of epidemiology, scope, and impact of spinal pain. Pain Physician 2009, 12:E35-70.

44. Willis BH: Spectrum bias - why clinicians need to be cautious when applying diagnostic test studies. Family Practice 2008, 25:390-396.

45. Lindström I, Öhlund C, Eek C, Wallin L, Peterson LE, Fordyce WE, Nachemson A: The effect of graded activity on patients with sub-acute low back pain: a randomized prospective clinical study with an operantconditioning behavioral approach. Phys Ther 1992, 72:279-293.

46. Loisel P, Abenhaim L, Durand P, Esdaile JM, Suissa S, Gosselin L, Simard R, Turcotte J, Lemaire J: A population-based, randomized clinical trial on back pain management. Spine 1997, 22:2911-2918.

47. Jensen IB, Bergstrom G, Ljungquist T, Bodin L: A 3-year follow-up of a multidisciplinary rehabilitation programme for back and neck pain. Pain 2005, 115:273-283.

48. Steenstra IA, Verbeek JH, Heymans MW, Bongers PM: Prognostic factors for duration of sick leave in patients sick listed with acute low back pain: a systematic review of the literature. Occup Environ Med 2005, 62:851-860.

49. Staal J, Hlobil H, van Tulder MW, Köke AJ, Smid T, van Mechelen W: Returnto-work interventions for low back pain: a descriptive review of contents and concepts of working mechanisms. Sports Med 2002, 32:251-267.

50. Lakke SE, Soer R, Takken T, Reneman MF: Risk and prognostic factors for non-specific musculoskeletal pain: a synthesis of evidence from systematic reviews classified into ICF dimensions. Pain 2009, 147:153-164.

51. Wasiak R, Young AE, Roessler RT, McPherson KM, van Poppel MN, Anema JR: Measuring return to work. J Occup Rehabil 2007, 17:766-781.

52. Waddell G, Watson PJ: Rehabilitation. Back Pain Revolution Edinburgh: Churchill LivingstoneWaddell G, 2 2004, 371-399.

53. Biering-Sørensen F, Thomsen C: Medical, social and occupational history as risk indicators for low-back trouble in a general population. Spine 1986, 11:720-725.

54. Mastekaasa A: Parenthood, gender and sickness absence. Soc Sci Med 2000, 50:1827-1842.

55. Åstrand NE, Isacsson SO: Back pain, back abnormalities, and competing medical, psychological, and social factors as predictors of sick leave, 
early retirement, unemployment, labour turnover and mortality: a 22 year follow up of male employees in a Swedish pulp and paper company. Br J Ind Med 1988, 45:387-395.

56. Waddell $G$, Waddell H: A review of social influences on neck and back pain and disability. Neck and back pain. The scientific evidence of causes, diagnosis, and treatment Philadelphia: Lippincott, Williams \& WilliamsNachemson A, Jonson E 2000, 13-55.

57. Linton SJ: Risk factors for neck and back pain in a working population in Sweden. Work \& Stress 1990, 4:41-49.

58. Tornqvist EW, Kilbom A, Vingård E, Alfredsson L, Hagberg M, Theorell T, Waldenström M, Wiktorin C, Hogstedt C, MUSIC-Norrtälje Study Group: The influence on seeking care because of neck and shoulder disorders from work-related exposures. Epidemiology 2001, 12:537-545.

59. Ghaffari M, Alipour A, Farshad AA, Jensen I, Josephson M, Vingård E: Effect of psychosocial factors on low back pain in industrial workers. Occup Med 2008, 58:341-347.

60. Theorell T, Perski A, Åkerstedt T: Changes in job strain in relation to changes in psychological state: a longitudinal study. Scand J Work Environ Health 1988, 14:189-196.

61. Hoogendoorn WE, van Poppel MN, Bongers PM, Koes BW, Bouter LM: Systematic review of psychosocial factors at work and private life as risk factors for back pain. Spine 2000, 25:2114-2125.

62. Selander J, Marnetoft SU, Bergroth A, Ekholm J: Return to work following vocational rehabilitation for neck, back and shoulder problems: risk factors reviewed. Disabil Rehabil 2002, 24:704-712.

63. Trief $P$, Stein M: Pending litigation and rehabilitation outcome of chronic low back pain. Arch Phys Med Rehabil 1985, 66:95-99.

64. Romelsjö A, Leifman H, Nyström S: A comparative study of two methods for the measurement of alcohol consumption in the general population. Int J Epidemiol 1995, 24:929-936.

65. Oleske DM, Lavender SA, Andersson GB, Morrissey MJ, Zold-Kilbourn P, Allen C, Taylor E: Risk factors for recurrent episodes of work-related low back disorders in an industrial population. Spine 2006, 31:789-798.

66. Neovius M, Janson A, Rössner S: Prevalence of obesity in Sweden. Obes Rev 2006, 7:1-3.

67. Sullivan M, Karlsson J, Ware JE Jr: The Swedish SF-36 Health Survey. I. Evaluation of data quality, scaling assumptions, reliability and construct validity across general populations in Sweden. Soc Sci Med 1995, 41:1349-1358

68. Nordin M, Hiebert R, Pietrek M, Alexander M, Crane M, Lewis S: Association of comorbidity and outcome in episodes of nonspecific low back pain in occupational populations. J Occup Environ Med 2002, 44:677-684.

69. Sanderson PL, Todd BD, Holt GR, Getty CJ: Compensation, work status, and disability in low back pain patients. Spine 1995, 20:554-556.

70. Jensen IB, Linton SJ: Coping strategies questionnaire (CSQ): reliability of the Swedish Version of the CSQ. Scand J Behaviour Therapy 1993, 22:139-145.

\section{Pre-publication history}

The pre-publication history for this paper can be accessed here: http://www.biomedcentral.com/1471-2296/11/53/prepub

doi:10.1186/1471-2296-11-53

Cite this article as: Lindell et al:: Predictors of stable return-to-work in non-acute, non-specific spinal pain: low total prior sick-listing, high self prediction and young age. A two-year prospective cohort study. BMC Family Practice 2010 11:53.

\section{Submit your next manuscript to BioMed Central and take full advantage of:}

- Convenient online submission

- Thorough peer review

- No space constraints or color figure charges

- Immediate publication on acceptance

- Inclusion in PubMed, CAS, Scopus and Google Scholar

- Research which is freely available for redistribution 